\title{
Effectiveness and safety of Humalog Mix 50/50 versus Humalog Mix 75/25 in Chinese patients with type 2 diabetes
}

This article was published in the following Dove Press journal:

Therapeutics and Clinical Risk Management

19 December 2014

Number of times this article has been viewed

\author{
Mohammad Ishraq Zafar ${ }^{1, *}$ \\ Xinquan $\mathrm{Ai}^{2, *}$ \\ Raja Adeel Shafqat ${ }^{3}$ \\ Feng Gao' \\ 'Department of Endocrinology, Union \\ Hospital, Tongji Medical College, \\ Huazhong University of Science and \\ Technology, Wuhan, People's Republic \\ of China; ${ }^{2}$ Zhijiang Petrochemical \\ Hospital, Zhijiang, People's Republic \\ of China; ${ }^{3}$ Department of Medicine, \\ Tongji Hospital, Tongji Medical \\ College, Huazhong University of \\ Science and Technology, Wuhan, \\ People's Republic of China \\ *These authors contributed equally \\ to this work
}

\begin{abstract}
Humalog Mix 75/25 insulin analog is widely used in the People's Republic of China to treat type 2 diabetes mellitus, but the Humalog Mix 50/50 analog is not as yet widely used or assessed. The purpose of this 12-week, parallel-group, randomized, treat-to-target study was to evaluate the difference in clinical efficacy, safety, and outcome of treatment between Humalog Mix 50/50 and Humalog Mix 75/25 analogs in Chinese patients with type 2 diabetes mellitus. In total, 146 insulin-naïve patients with type 2 diabetes mellitus and aged 18-75 years were randomized and treated twice a day with either Humalog Mix 50/50 (group A) or Humalog Mix 75/25 (group B). We monitored levels of fasting blood glucose, 2-hour postprandial blood glucose, and glycosylated hemoglobin $\left(\mathrm{HbA}_{1 \mathrm{c}}\right)$ in patients in both groups prior to and 3 months post treatment, the average time to achieve target blood glucose level, and frequency of hypoglycemic episodes during treatment. We found that group A showed better glycemic control as per fasting blood glucose and 2-hour postprandial blood glucose than group B. Moreover, $\mathrm{HbA}_{1 \mathrm{c}}$ levels in group A $(5.5 \% \pm 1.4 \%)$ were lower by $1.0 \% \pm 0.1 \%(P<0.05)$ compared with those in group B $(6.5 \% \pm 1.5 \%)$. The time to achieve glucose control was shorter $(P<0.05)$ in group A (12.6 \pm 3.6 days) than in group B (22.3 \pm 4.7 days). Regarding safety, no significant adverse events or severe hypoglycemia on treatment was observed in either group. Additionally, the 1:1 ratio of Humalog Mix 50/50 showed a trend towards fewer episodes of nocturnal hypoglycemia. Thus, compared with Humalog Mix 75/25, the high-proportion premix insulin analog, Humalog Mix 50/50 showed better glycemic control, achieved target blood glucose levels more rapidly and without an increase in hypoglycemic episodes in Chinese type 2 diabetic individuals and is recommended for use in clinical practice.
\end{abstract}

Keywords: type 2 diabetes mellitus, Chinese type 2 diabetics, Humalog Mix 50/50, Humalog Mix 75/25, premixed insulin lispro 50/50, premixed insulin lispro 75/25

\section{Introduction}

Regional analysis by the International Diabetes Federation portrays South-East Asia as having approximately 72.1 million of the 382 million people affected by diabetes around the world, with a global projection of a $71 \%$ increase by $2035 .{ }^{1}$ More specifically, the People's Republic of China has been rated first among the top ten countries/ territories with the highest number of diabetes patients aged 20-79 years in 2013, representing approximately 98.4 million people. ${ }^{1}$ The other top ten countries after the People's Republic of China include India, the USA, Brazil, Russia, Mexico, Indonesia, Germany, Egypt, and Japan. ${ }^{1}$

Insulin is an effective treatment for lowering abnormal blood glucose levels and can also postpone the development of insulin resistance. ${ }^{2}$ A good understanding of the physiology and pharmacokinetics of insulin will ensure a better treatment outcome.
Department of Endocrinology, Union Hospital, Tongji Medical College, Huazhong University of Science and Technology, 1277 Jiefang Avenue, Wuhan, Hubei, People's Republic of China

$\mathrm{Tel}+8613971525208$

Fax +862785356365

Email gaofengwh@aliyun.com 
When compared with human premixed insulin, premixed insulin analogs can provide better glucose control in both postprandial and fasting hyperglycemia, as well as a lower risk of hypoglycemia. ${ }^{3}$ Moreover, premixed analogs are absorbed more rapidly than human premixed insulin, which allows their use just before a meal or within 15 minutes after a meal, ultimately leading to better compliance on the part of patients. ${ }^{4}$

Humalog Mix 75/25 is a low-proportion, premixed ana$\log$ containing 25\% lispro insulin (rapid-acting) and 75\% lispro-protamine insulin (longer-acting). On the other hand, Humalog Mix 50/50 is a high-proportion, premixed insulin containing 50\% lispro insulin and 50\% lispro-protamine insulin. The rapid-acting lispro insulin in Humalog provides good postprandial glycemic control while the longer-acting lispro protamine supplies insulin during fasting. ${ }^{5}$ Both premixed insulin analogs are effective and safe in the long-term treatment of patients with type 2 diabetes mellitus. ${ }^{3,6}$

According to a study conducted in the USA, Humalog Mix 50/50 and Humalog Mix 75/25 are equipotent in targeting overall glycemic control and postprandial glycemic control. Also, they both cause less nocturnal hypoglycemia. ${ }^{6}$ The efficacy outcome of Humalog Mix 75/25 given twice daily is well documented in Chinese patients with type 2 diabetes; ${ }^{7}$ however, use of Humalog Mix 50/50 in Chinese patients is not as well understood.

This 12-week, parallel-group, randomized, treat-totarget study was done to test the hypothesis that twice-daily Humalog Mix 50/50 is superior to Humalog Mix 75/25 in lowering blood glucose levels among Chinese patients with diabetes. If so, Humalog Mix 50/50 will provide an alternative to existing treatment modalities for improving the rate of blood glucose control in type 2 diabetic patients in the People's Republic of China.

\section{Materials and methods}

\section{Inclusion and exclusion criteria}

A total of 146 patients out of 200 with type 2 diabetes (Figure 1) were included in this study between January and March 2014 on the basis of the World Health Organization diagnostic criteria for diabetes. ${ }^{8}$ Male and female patients aged 18-75 years with a body mass index $\leq 32 \mathrm{~kg} / \mathrm{m}^{2}$ and who had previously received one or more oral antidiabetic drugs for at least 3 months with poor glycemic control (fasting blood glucose $\geq 7.8$ $\mathrm{mmol} / \mathrm{L}$; glycosylated hemoglobin $\left[\mathrm{HbA}_{1 \mathrm{c}}\right] \geq 7.5 \%$ ) before randomization were included. Patients had not received insulin therapy prior to the study. No patients received treatments that interfered with glucose metabolism or had any condition that would interfere with study participation or evaluation of the results. Patients with type 1 diabetes or gestational diabetes, those aged younger than 18 years or older than 75 years, those with a body mass index $>32 \mathrm{~kg} / \mathrm{m}^{2}$, drug-naïve or previously insulin-treated patients, those with fair glycemic control (fasting blood glucose $[\mathrm{FBG}]<7.8 \mathrm{mmol} / \mathrm{L} ; \mathrm{HbA}_{1 \mathrm{c}}<7.5 \%$ ), and those with severe diseases such as anemia, kidney disease, or liver disease were excluded from the study.

\section{Participants}

A total of 146 insulin-naïve patients with type 2 diabetes mellitus discontinued all oral antidiabetic drugs (including metformin, acarbose, and sulfonylureas) and were randomized to receive either Humalog Mix 50/50 (group A) or Humalog Mix 75/25 (group B). Each group included 73 cases. The patient characteristics of each group are listed in Table 1. There was no statistically significant difference between the two groups in terms of sex, age, body mass index, disease duration, baseline FBG, 2-hour postprandial blood glucose (P2hBG), or $\mathrm{HbA}_{1 \mathrm{c}}(P>0.05)$.

\section{Treatment}

Patients in groups A and B were given subcutaneous injections of either Humalog Mix 50/50 or Humalog Mix 75/25, respectively, twice a day for 12 weeks. Both drugs are produced by Eli Lilly Company (Indianapolis, IN, USA). All patients discontinued their previous oral antidiabetic drugs at randomization with no wash-out period. Patients in both groups received similar suggestions from the investigators with regard to food intake and lifestyle.

For this study, insulin doses were initiated at $0.4 \mathrm{U} / \mathrm{kg}$ and divided equally in the morning and evening (immediately before breakfast and dinner). Later, the dosage was adjusted according to the patient's blood glucose levels. A titration algorithm similar to that used in a previous study of insulin

Table I Patient characteristics in each group

\begin{tabular}{lll}
\hline & Group A & Group B \\
\hline Number of patients (of I46 total) & 73 & 73 \\
Number of males/females & $38 / 35$ & $40 / 33$ \\
Age range (years) & $39-72$ & $45-76$ \\
Mean \pm SD age (years) & $57.8 \pm 2.2$ & $59.2 \pm 2.5$ \\
Mean BMI & 24.83 & 24.79 \\
Duration of illness range (years) & $1-14$ & $3-15$ \\
Mean \pm SD duration of illness (years) & $5.6 \pm I .5$ & $5.8 \pm 1.7$ \\
Mean \pm SD pre-treatment FBG (mmol/L) & $8.9 \pm I .8$ & $8.7 \pm 1.7$ \\
Mean \pm SD pre-treatment P2hBG (mmol/L) & $11.7 \pm I .8$ & $11.6 \pm 1.8$ \\
Mean \pm SD pre-treatment HbA ${ }_{\text {Ic }}(\%)$ & $9.7 \pm I .5$ & $10.1 \pm 1.6$ \\
\hline
\end{tabular}

Abbreviations: $\mathrm{BMI}$, body mass index; $\mathrm{FBG}$, fasting blood glucose; $\mathrm{HbA}_{1 \mathrm{l}}$, glycosylated hemoglobin; P2hBG, 2-hour postprandial blood glucose; SD, standard deviation. 
Table 2 Insulin dose titration algorithm

\begin{tabular}{lll}
\hline $\begin{array}{l}\text { Range of FBG or pre-dinner SMBG } \\
(\mathbf{m g} / \mathbf{d L})\end{array}$ & Insulin dose adjustment \\
\hline$<80$ & $<4.4$ & $-2 \mathrm{U}$ \\
$80-110$ & $4.4-6.1$ & - \\
$\mathrm{II}-140$ & $6.2-7.8$ & $+2 \mathrm{U}$ \\
$|4|-180$ & $7.83-10$ & $+4 \mathrm{U}$ \\
$>180$ & $>10$ & $+6 \mathrm{U}$ \\
\hline
\end{tabular}

Abbreviations: SMBG, self-monitoring of blood glucose; FBG, fasting blood glucose.

therapy in type 2 diabetes was adopted. ${ }^{9}$ Either FBG or equivalent pre-dinner self-measured blood glucose values were used to calculate adjustments of dosage (see Table 2).

\section{Parameters}

We monitored FBG, $\mathrm{P} 2 \mathrm{hBG}$, and $\mathrm{HbA}_{1 \mathrm{c}}$ levels in both groups prior to and post treatment. FBG and $\mathrm{P} 2 \mathrm{hBG}$ levels were evaluated using the glucose oxidase method and $\mathrm{HbA}_{1 \mathrm{c}}$ levels were assessed by high performance liquid chromatography. We also recorded the average time taken to achieve blood glucose control (defined as FBG and pre-dinner blood glucose targets of 4.4 to $6.1 \mathrm{mmol} / \mathrm{L}){ }^{10}$

Episodes of hypoglycemia (including major, minor, and nocturnal hypoglycemia) were recorded during the study. Major hypoglycemia was defined as an episode with neurological symptoms consistent with hypoglycemia that could not be self-treated by the patient. Minor hypoglycemia was defined as episodes that were self-treated and with a confirmed blood glucose reading $\leq 3.9 \mathrm{mmol} / \mathrm{L} .{ }^{10}$ Nocturnal hypoglycemia was reported by the patient when she/he experienced hypoglycemic symptoms during night.

Insulin dose and weight gain were also assessed at the end of the trial. Adverse events were recorded throughout the study. Standard laboratory parameters such as blood routine (including blood counts, hemoglobin percentage, erythrocyte sedimentation rate) were evaluated at the beginning and end of the study.

\section{Statistical analysis}

We used Statistical Package for the Social Sciences version 16.0 software (SPSS Inc, Chicago, IL, USA) to analyze the data. The quantitative data are expressed as the mean \pm standard deviation. The comparison between groups was done using the chi-square test, with a difference being regarded as statistically significant at $P<0.05$.

\section{Results \\ Efficacy}

After treatment, $\mathrm{FBG}, \mathrm{P} 2 \mathrm{hBG}$, and $\mathrm{HbA}_{1 \mathrm{c}}$ levels decreased significantly in both groups (see Table 3 ) and the difference between pre-treatment and post-treatment levels in each group was statistically significant $(P<0.05)$. The mean changes in FBG (-2.6 mmol/L), P2hBG (-4.2 mmol/L), and $\mathrm{HbA}_{1 \mathrm{c}}(-4.2 \%)$ in group $\mathrm{A}$ were significantly larger than those in FBG $(-1.1 \mathrm{mmol} / \mathrm{L}), \mathrm{P} 2 \mathrm{hBG}(-2.0 \mathrm{mmol} / \mathrm{L})$, and $\mathrm{HbA}_{1 \mathrm{c}}(-3.6 \%)$ in group $\mathrm{B}$, respectively, $(P<0.05$; see Table 3$)$. The average time taken to reach glycemic target by group A $(12.6 \pm 3.6$ days) was significantly $(P<0.05)$ shorter than that of group B (22.3 \pm 4.7 days).

\section{Hypoglycemia}

During the treatment, five cases (five events) in group A and four cases (six events, two of which were nocturnal) in group B had minor hypoglycemic episodes (see Table 4). There was no significant difference between the two groups. No major hypoglycemic episodes were experienced by any patient in either group.

\section{Insulin dose and weight gain}

At the end of the study, there was no significant difference in the total daily insulin dose between the two groups $(0.84 \pm 0.31 \mathrm{U} / \mathrm{kg}$ for group $\mathrm{A}$ and $0.87 \pm 0.27 \mathrm{U} / \mathrm{kg}$ for group B, $P=0.17$, see Table 5). The 1:1 split of the total insulin daily dose initiated at the start of the trial was maintained throughout the study (pre-breakfast and pre-dinner doses in group A were $0.45 \pm 0.14$ and $0.47 \pm 0.16$ units $/ \mathrm{kg}$ and in group B were $0.46 \pm 0.15$ and $0.48 \pm 0.17 \mathrm{U} / \mathrm{kg}$, respectively; see Table 5). Weight increased significantly in both treatment groups. In group A, the increase was $1.92 \pm 0.31 \mathrm{~kg}$ (95\% confidence interval 2.124-3.865) and in group B was $2.03 \pm 0.29 \mathrm{~kg}$ ( $95 \%$ confidence interval 2.358-3.493).

Table 3 FBG, $\mathrm{P} 2 \mathrm{hBG}$, and $\mathrm{HbA}$ IC levels prior to and after treatment in the two groups

\begin{tabular}{|c|c|c|c|c|c|c|}
\hline & \multicolumn{2}{|l|}{ FBG (mmol/L) } & \multicolumn{2}{|c|}{ P2hBG (mmol/L) } & \multicolumn{2}{|l|}{$\mathrm{HbA}_{\mathrm{IC}}(\%)$} \\
\hline & Pre-treatment & Post-treatment & Pre-treatment & Post-treatment & Pre-treatment & Post-treatment \\
\hline Group A & $8.9 \pm 1.8$ & $6.3 \pm 1.3 * \Delta$ & $\mathrm{II} .7 \pm \mathrm{I} .8$ & $7.5 \pm 1.3^{*} \Delta$ & $9.7 \pm 1.5$ & $5.5 \pm 1.4^{*} \Delta$ \\
\hline Group B & $8.7 \pm 1.7$ & $7.6 \pm 1.5$ & $11.6 \pm 1.8$ & $9.6 \pm 1.5$ & $10.1 \pm 1.6$ & $6.5 \pm 1.5$ \\
\hline
\end{tabular}

Notes: Data are shown as the mean \pm standard deviation. *Statistically significant (compared with pre-treatment), $P<0.05$. $\Delta$ indicates statistical significance compared with group $B, P<0.05$.

Abbreviations: FBG, fasting blood glucose; $\mathrm{HbA}_{1 \mathrm{c}}$, glycosylated hemoglobin; P2hBG, 2-hour postprandial blood glucose. 
Table 4 Hypoglycemia

\begin{tabular}{|c|c|c|c|c|}
\hline & \multicolumn{2}{|c|}{ Humalog Mix 50/50 } & \multicolumn{2}{|c|}{ Humalog Mix 75/25 } \\
\hline & n (\%) & Event & n (\%) & Event \\
\hline Number & 7 & 3 & 7 & 3 \\
\hline Minor & $5(6.84 \%)$ & 5 & $4(5.48 \%)$ & 6 \\
\hline Major & 0 & & 0 & \\
\hline Nocturnal & 0 & & $2(2.74 \%)$ & 2 \\
\hline
\end{tabular}

There was no significant difference in weight gain between the two groups.

\section{Other safety parameters}

No other adverse events were noted in the two groups. The laboratory results for blood chemistry and hematology at the end of the trial were similar to those at baseline in both groups.

\section{Discussion}

Type 2 diabetes mellitus occurs only when the body does not produce enough insulin due to insulin resistance. ${ }^{1}$ To overcome the deficit in insulin and to control the glycemic level, exogenous insulin is the best possible treatment when compared with other hypoglycemic agents. ${ }^{11}$ Different forms of insulin analogs are available for the treatment of diabetes. Premixed insulin analogs are considered effective for treatment of type 2 diabetes. They can be given singly or combined with other hypoglycemic agents. ${ }^{12}$ Patients treated with the premixed insulin analogs Humalog Mix 75/25 or $50 / 50$ twice daily are found to achieve glycemic targets of $\mathrm{HbA}_{1 \mathrm{c}}$ more rapidly than patients on basal analogs. ${ }^{13}$ A recent study ${ }^{5}$ of type 2 diabetes mellitus patients in the People's Republic of China showed that when fasting hyperglycemia is prevalent a premixed analog with more basal insulin (such as Humalog Mix 75/25) may be more appropriate, and that when postprandial hyperglycemia is prevalent, a premixed analog with more rapid-acting insulin (such as Humalog Mix 50/50) may be more appropriate. However, Humalog Mix 50/50 has not been widely used or investigated in the People's Republic of China. Moreover, there is no report of any direct comparison between
Humalog Mix 50/50 and Humalog Mix 75/25 in Chinese patients with diabetes.

The aim of this study was to provide an additional treatment option for Chinese diabetics to improve the rate of blood glucose control. We compared the clinical efficacy, safety, and outcome of treatment with Humalog Mix 75/25 and Humalog Mix 50/50 in Chinese patients with type 2 diabetes. In terms of clinical efficacy (FBG, P2hBG, and $\mathrm{HbA}_{1 \mathrm{c}}$ ), we found that treatment with Humalog Mix 50/50 achieved better glycemic control than Humalog Mix 75/25. There was a decrease in FBG in group A (Humalog Mix 50/50) compared with group B (Humalog Mix 75/25), with a difference of $1.3 \pm 0.2 \mathrm{mmol} / \mathrm{L}$. In addition, while comparing postprandial glucose levels in the treatment groups, we found that Humalog Mix 50/50 resulted in better postprandial glycemic control, with a difference of $2.1 \pm 0.3 \mathrm{mmol} / \mathrm{L}$. We also observed that $\mathrm{HbA}_{1 \mathrm{c}}$ levels of patients in group A (Humalog Mix 50/50) were lower by $1.0 \% \pm 0.1 \%(P<0.05)$ compared with those of patients in group B (Humalog Mix 75/25). Moreover, group A patients achieved their glycemic target more rapidly (9.7 \pm 1.1 days earlier) than group B patients.

It is well known that postprandial glucose level contributes more to the $\mathrm{HbA}_{1 \mathrm{c}}$ level than FBG when $\mathrm{HbA}_{1 \mathrm{c}}$ approaches target. ${ }^{14}$ Unlike Caucasian diabetics, $88 \%$ of Chinese patients with type 2 diabetes have isolated or combined postprandial hyperglycemia. ${ }^{15}$ This is attributed to two reasons: carbohydrate, with the highest glycemic index, is a dominant component of the Chinese diet; ${ }^{16}$ and Chinese patients with diabetes exhibit severe insulin secretion insufficiency, especially postprandially, which results in prominent postprandial hyperglycemia. ${ }^{17}$ Since Humalog Mix 50/50 contains a higher proportion of short-acting insulin than Humalog Mix 75/25, it gives rise to better postprandial glycemic control which targets the major pathophysiological features in Chinese type 2 diabetics as described earlier. This indicates that Humalog Mix 50/50 is more suitable for use in Chinese patients with diabetes.

According to a previous study, ${ }^{18}$ when individuals without diabetes have a meal, their basal to postprandial insulin secretion is approximately $1: 1$. In addition, patients with

Table 5 Insulin dose at the end of the study $(\mathrm{U} / \mathrm{kg})$

\begin{tabular}{llllll}
\hline & Humalog Mix 50/50 & & & \multicolumn{2}{l}{ Humalog Mix 75/25 } \\
\cline { 2 - 3 } & Pre-breakfast & Pre-dinner & & Pre-breakfast & Pre-dinner \\
\hline Mean (SD) & $0.45 \pm 0.14$ & $0.47 \pm 0.16$ & & $0.46 \pm 0.15$ & $0.48 \pm 0.17$ \\
Ratio & $49 \%$ & $51 \%$ & $51 \%$ & $49 \%$ \\
Total daily dose, mean (SD) & $0.84 \pm 0.31 \mathrm{U} / \mathrm{kg}$ & & $0.87 \pm 0.27 \mathrm{U} / \mathrm{kg}$ & \\
\hline
\end{tabular}

Abbreviation: SD, standard deviation. 


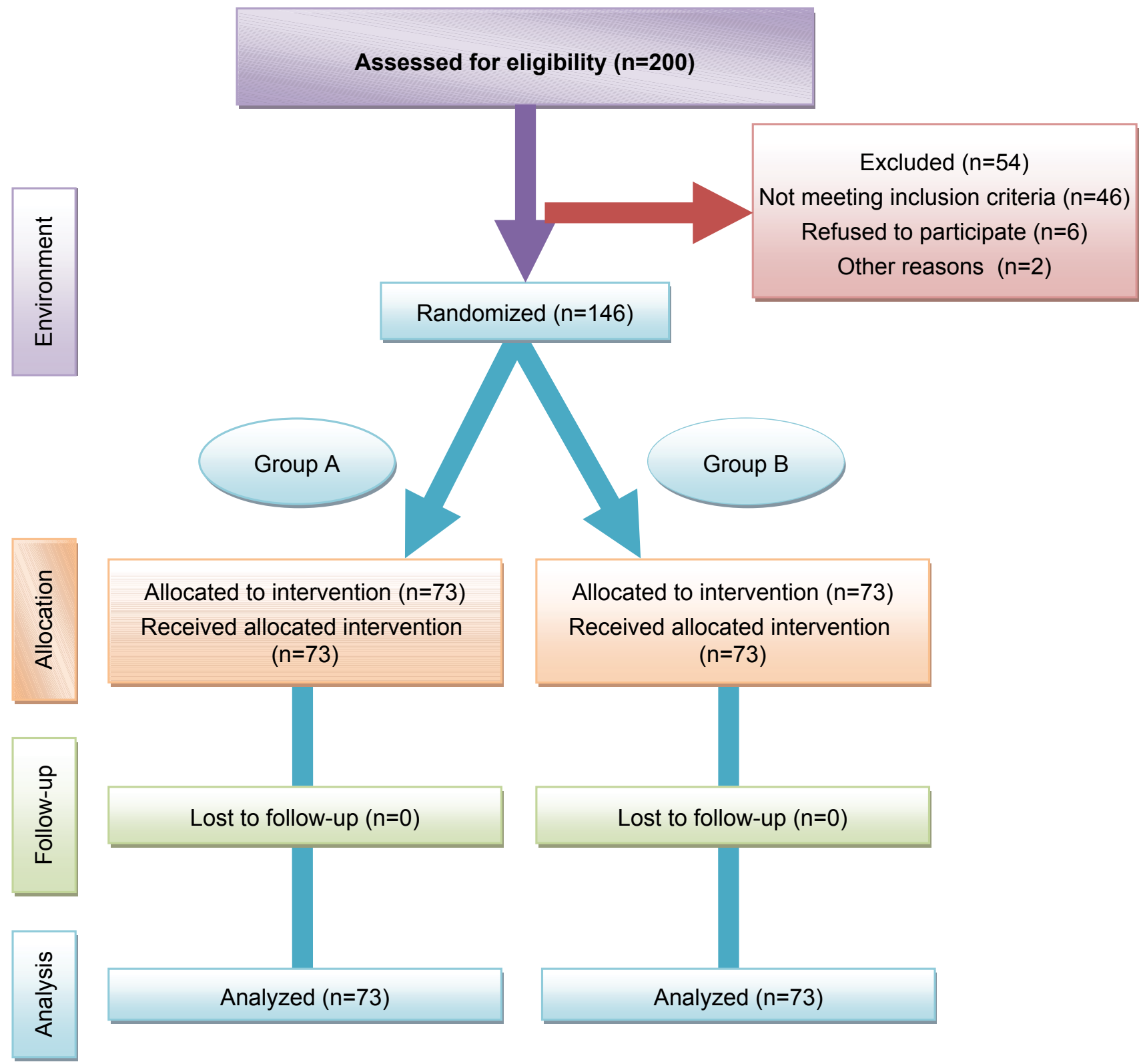

Figure I Flow chart showing patient disposition.

type 2 diabetes mellitus who have received insulin treatment and achieved glycemic control have a similar physiological insulin secretion proportion of 1:1 ratio in the insulin used. ${ }^{19}$ This confirms our finding that Humalog Mix 50/50 has better efficacy than Humalog Mix 75/25.

In terms of safety, there were no significant adverse events or reports of severe hypoglycemia during treatment with either Humalog Mix 50/50 or Humalog Mix 75/25. However, it was observed that the 1:1 ratio of Humalog Mix $50 / 50$ showed a tendency to reduce the occurrence of nocturnal hypoglycemia when compared with the ratio of Humalog Mix 75/25, although it was not significant (see Table 4).
This may be attributed to Humalog Mix 75/25 containing more basal insulin than Humalog Mix 50/50.

A limitation of this study is the limited number of patients. The small sample size limits the generalizability of the study. A small sample size may lead to a type 2 error (ie, accepting the null hypothesis when it is false).$^{20}$ However, our study can be considered as a "pilot study" to inspire more research on the topic. Future research with a larger sample size of Chinese diabetic patients may be needed to overcome this limitation.

In conclusion, our study findings show that Humalog Mix 50/50 is clinically more efficient than Humalog Mix 75/25 in 
terms of FBG, $\mathrm{P} 2 \mathrm{hBG}$, and $\mathrm{HbA}_{1 \mathrm{c}}$ levels. Moreover, Huma$\log$ Mix 50/50 allowed for a shorter time required to reach the glycemic target as compared with Humalog Mix 75/25. In addition, Humalog Mix 50/50 showed a safety profile similar to that as Humalog Mix 75/25. Therefore, Humalog Mix $50 / 50$ is considered suitable for more widespread clinical use to improve the rate of blood glucose control in patients with type 2 diabetes mellitus in the People's Republic of China.

\section{Acknowledgments}

The authors thank all doctors and medical staff at the Department of Endocrinology, Union Hospital, for their help and guidance during this study, which was supported by Scientific Research Grants, Ministry of Education, People's Republic of China.

\section{Disclosure}

The authors report no conflicts of interests in this work.

\section{References}

1. International Diabetes Federation. IDF Diabetes Atlas. 6th ed. Brussels, Belgium: International Diabetes Federation; 2013. Available from: http:// www.idf.org/diabetesatlas. Accessed November 18, 2014.

2. Juurinen L, Tiikkainen M, Häkkinen AM, Hakkarainen A, Yki-Järvinen H. Effects of insulin therapy on liver fat content and hepatic insulin sensitivity in patients with type 2 diabetes. Am J Physiol Endocrinol Metab.2007;292(3):E829-E835.

3. Levit S, Toledano Y, Wainstein J. Improved glycaemic control with reduced hypoglycaemic episodes and without weight gain using longterm modern premixed insulins in type 2 diabetes. Int $J$ Clin Pract. 2011;65(2):165-171.

4. Yki-Järvinen H. Combination therapies with insulin in type 2 diabetes. Diabetes Care. 2001;24(4):758-767.

5. Li W, Min R, Dong Y, Li Z, Sun Q, Li Y. Using continuous glucose monitoring to measure glucose variation of patients with type 2 diabetes: switching from premixed human insulin 70/30 to insulin lispro mix 75/25 or lispro mix 50/50 for 8 weeks. Journal of Diabetes Research and Clinical Metabolism. 2013:2(15).

6. Roach P, Trautmann M, Arora V, Sun B, Anderson JH Jr. Improved postprandial blood glucose control and reduced nocturnal hypoglycemia during treatment with two novel insulin lispro-protamine formulations, insulin lispro mix25 and insulin lispro mix50. Mix50 Study group. Clin Ther. 1999;21(3):523-534.
7. Li Y, Li Q, Li CJ, et al. Comparison of $\mathrm{HbA}_{1 c}$ in Chinese patients with type 1 or type 2 diabetes randomized to twice daily insulin lispro low mix 25 or twice daily human insulin mix 30/70. Chin Med J (Engl). 2009;122(21):2540-2546.

8. World Health Organization. Definition and diagnosis of diabetes mellitus and intermediate hyperglycemia, 2006. Available from: http:// whqlibdoc.who.int/publications/2006/9241594934_eng.pdf. Accessed November 18, 2014.

9. Raskin P, Allen E, Hollander P, et al; for INITIATE study group. Initiating insulin therapy in type 2 diabetes: a comparison of biphasic and basal insulin analogs. Diabetes Care. 2005;28(2):260-265.

10. Yang W, Ji Q, Zhu D, et al. Biphasic insulin aspart 30 three times daily is more effective than a twice-daily regimen, without increasing hypoglycemia, in Chinese subjects with type 2 diabetes inadequately controlled on oral antidiabetes drugs. Diabetes Care. 2008;31(5): 852-856.

11. Lingvay I, Legendre JL, Kaloyanova PF, Zhang S, Adams-Huet B, Raskin $P$. Insulin-based versus triple oral therapy newly diagnosed type 2 diabetes: which is better? Diabetes Care. 2009;32(10):1789-1795.

12. Ilag LL, Kerr L, Malone JK, Tan MH. Prandial premixed insulin analogue regimens versus basal insulin analogue regimens in the management of type 2 diabetes: an evidence-based comparison. Clin Ther. 2007;29(6 Pt 1):1254-1270.

13. Rolla AR, Rakel RE. Practical approaches to insulin therapy for type 2 diabetes mellitus with premixed insulin analogues. Clin Ther. 2005; 27(8):1113-1125.

14. Monnier L, Lapinski H, Colette C. Contributions of fasting and postprandial plasma glucose increments to the overall diurnal hyperglycemia of type 2 diabetic patients: variations with increasing levels of $\mathrm{HbA}(1 \mathrm{c})$. Diabetes Care. 2003;26(3):881-885.

15. Jia WP, Pang C, Chen L, et al. Epidemiological characteristics of diabetes mellitus and impaired glucose regulation in a Chinese adult population: the Shanghai Diabetes Studies, a cross-sectional 3-year follow-up study in Shanghai urban communities. Diabetologia. 2007; 50(2):286-292.

16. Li LM, Rao KQ, Kong LZ, et al. [A description on the Chinese national nutrition and health survey in 2002]. Zhonghua Liu Xing Bing Xue Za Zhi. 2005;26(7):478-484. Chinese.

17. An YL, Gao Y, Zhu Q, et al. [Features of insulin secretion and insulin resistance in newly diagnosed type 2 diabetes of different body mass indices]. Zhonghua Yi Xue Za Zhi. 2009;89(16):1117-1121. Chinese.

18. Polonsky KS, Given BD, Van Cauter E. Twenty-four-hour profiles and pulsatile patterns of insulin secretion in normal and obese subjects. J Clin Invest. 1988;81(2):442-448.

19. Herman WH, Ilag LL, Johnson SL, et al. A clinical trial of continuous subcutaneous insulin infusion versus multiple daily injections in older adults with type 2 diabetes. Diabetes Care. 2005;28(7):1568-1573.

20. Ibrahim IA, Beich J, Sidorov J, Gabbay R, Yu L. Measuring outcomes of type 2 diabetes disease management program in an HMO setting. South Med J. 2002;95(1):78-87.
Therapeutics and Clinical Risk Management

\section{Publish your work in this journal}

Therapeutics and Clinical Risk Management is an international, peerreviewed journal of clinical therapeutics and risk management, focusing on concise rapid reporting of clinical studies in all therapeutic areas, outcomes, safety, and programs for the effective, safe, and sustained use of medicines. This journal is indexed on PubMed Central, CAS,

\section{Dovepress}

EMBase, Scopus and the Elsevier Bibliographic databases. The manuscript management system is completely online and includes a very quick and fair peer-review system, which is all easy to use. Visit http://www.dovepress.com/testimonials.php to read real quotes from published authors. 